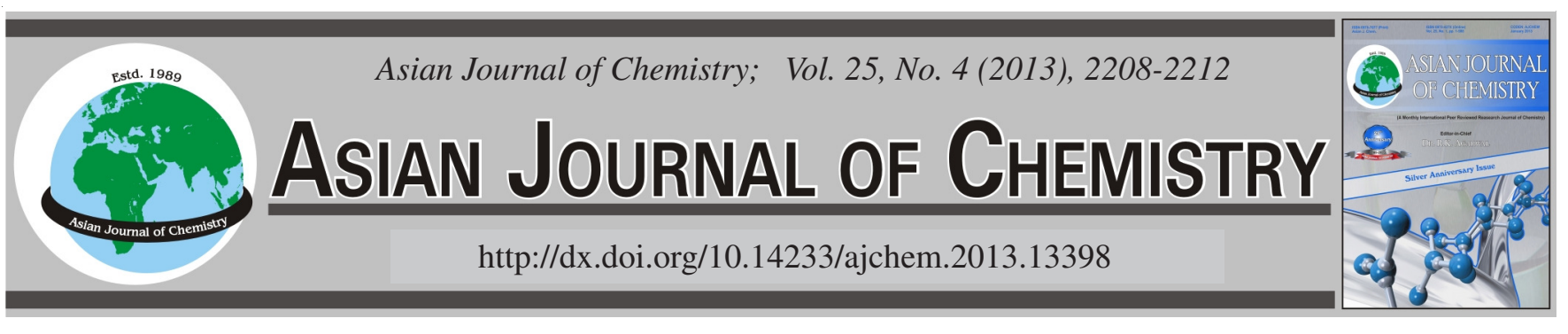

\title{
Cloud Point Extraction Coupled with Ultrasonic-assisted for Determination of Au and Ag in Water Samples by Flame Atomic Absorption Spectrometry
}

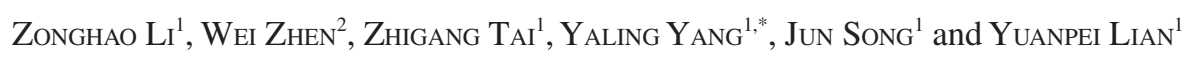

${ }^{1}$ Faculty of Life Science and Technology, Kunming University of Science and Technology, Yunnan Province 650500, P.R. China

${ }^{2}$ Kunming Fruit Business and Economics Co. Ltd., Kunming 650106, P.R. China

*Corresponding author: Tel: +86 138 88316388, 136 98745785; E-mail: yilyil8@163.com, lizonghaoyjq@163.com

(Received: 6 January 2012;

Accepted: 17 October 2012)

AJC-12313

\begin{abstract}
A simple and practical preconcentration method was developed for the cloud point extraction of gold and silver. The method is based on the formation of hydrophobic complexes of gold and silver ions with sodium diethyldithiocarbamate (Na-DDTC) and Dow Corning DC193 was added as a non-ionic surfactant. The phase diagrams of the binary system, water-surfactant (DC-193) and the ternary system, water-surfactant-fatty acids (nonanoic acid), were determined. Under the optimal conditions, the calibration curves were linear in the range of $10-500 \mu \mathrm{g} / \mathrm{L}$ and $10-800 \mu \mathrm{g} / \mathrm{L}$ with the detection limits of $3.4 \mu \mathrm{g} / \mathrm{L}$ and $2.7 \mu \mathrm{g} / \mathrm{L}$ for gold and silver, respectively. The enrichment factors are 25 and 20 for gold and silver, respectively. The relative standard deviations are $3.6 \%$ for gold and $3.4 \%$ for silver ( $\mathrm{n}=11$ ). The method was successfully applied to the determination of gold and silver in water samples.
\end{abstract}

Key Words: Gold, Silver, Dow Corning DC-193, Cloud point extraction, Flame atomic absorption spectrometry.

\section{INTRODUCTION}

Gold and silver are both noble metals and distribute in mine samples and environmental samples with low concentration. They are valuable metals due to their attractive physical and chemical character and wide range of applications such as in biomedicine, automatics, jewelry, chemical industry, energy and process technology ${ }^{1}$. Often, the concentrations of $\mathrm{Au}$ and $\mathrm{Ag}$ in mine and environmental samples are lower than the detection limit of flame atomic absorption spectroscopy. The noble metals are one of the most difficult groups of elements to be accurately determined at low concentration levels ${ }^{2}$. Gold and silver usually occur together in mine and environmental samples and making the determination of the two noble metals at trace levels are still a challenging task for analysts $^{3}$.

Cloud point extraction is a multipurpose and simple method for separating and preconcentrating metal ions, which can improve the detection limit and enhance the atomic absorption spectrometry's sensitivity and selectivity ${ }^{4-8}$. It is on the basis of the behaviour of non-ionic surfactant aqueous solutions, that exhibit a phase separation by changing the temperature ${ }^{2}$. Cloud point is the temperature that an aqueous solution of a water-soluble surfactant becomes turbid. When heating the surfactant solution over the critical temperature, the solution is easily separated into two distinct phases: a surfactant-rich phase of small volume and a diluted aqueous phase $^{9}$. And the hydrophobic compounds which present in the solution and bound to the micells are extracted to the surfactant-rich phase.

Some ligands such as O,O-diethyl-dithiophosphate (DDTP), bis-((1H-benzo[d]imidazol-2yl)ethyl) sulfane (BIES), 1,8-diamino-4,5-dihyroxyanthraquinone, dithizone,1-phenyl3-methyl-4-benzoyl-5-pyrazolone (PMBP), thiosemicarbazone and Brilliant green have been used to determinate $\mathrm{Au}$ or $\mathrm{Ag}$ by the method of cloud point extraction ${ }^{1,3,10-15}$. The method based on the cloud point extraction of gold without a chelating agent had also been reported ${ }^{6,16}$. The surfactants used in the cloud point extraction processes mostly are Triton series and PONPE series ${ }^{17-20}$. Dow Corning DC-193 (Fig. 1) is a silicone surfactant. It is an environmental friendly non-ionic surfactant which has no background absorbance in the ultraviolet area due to its structural feature. And it have high flexible polysiloxane chains with low cohesive energy, which offer more conformations than traditional surfactants and results in compact micelle structure as well as low water content in the surfactant-rich phase ${ }^{21}$.

In this work, Dow Corning DC-193 was used as a new surfactant in the process of cloud point extraction preconcentration for the determination of $\mathrm{Au}$ and $\mathrm{Ag}$ in mine samples, using DDTC as a frequently-used complexing agent with satisfactory results. Following preconcentration, the analytes 
were determined in the surfactant-rich phase by flame atomic absorption spectrometry.<smiles>CCCO[Si](C)(CCCO)O[Si](C)(C)O[Si](C)(C)C</smiles>

Fig. 1. Structure of DC-193

\section{EXPERIMENTAL}

The $\mathrm{pH}$ values were measured using a pHSJ-4A pH meter equipped with a glass-combination electrode (Shanghai Precision and Scientific Instrument Corp., China). SK5210LHC ultrasonic instrument was employed for the cloud point experiments (Shanghai kudos ultrasonic instrument Limited Company, China) and flame atomic absorption spectrometer (AA6300, Shimadzu, Japan) was used for the determination of the concentration of metal. All the reagents used were of analytical reagent grade and all solutions were prepared in deionized water.

A stock standard solution of gold and silver at a concentration of $1000 \mu \mathrm{g} / \mathrm{mL}$ and $10 \%$ (v/v) of DC-193 and Triton $\mathrm{X}-114$ were used.

General procedure: For the cloud point extraction, aliquots of working standard solution of $\mathrm{Au}$ and $\mathrm{Ag}(0.5 \mu \mathrm{g} / \mathrm{mL})$, $7.0 \mu \mathrm{g} / \mathrm{mL}$ DDTC for Au and Ag, respectively, $1.5 \mathrm{~mL} 10 \%$ (v/v) DC-193 and $0.8 \mathrm{~mL}$ nonanoic acid were placed in a 10 $\mathrm{mL}$ screw cap glass centrifuge tube with conical bottom. The mixtures were diluted to $10 \mathrm{~mL}$ with deionized water. Then, the glass centrifuge tube was put in ultrasonic instrument for $20 \mathrm{~min}$. After that, the mixtures were heated at $65^{\circ} \mathrm{C}$ for 50 min. After phase separation, the aqueous phase was then removed from the centrifuge tube by a syringe. The surfactantrich phase was diluted with methanol solution containing 1.0 mol L-1 $\mathrm{HNO}_{3}$ to $1.0 \mathrm{~mL}$ and then the analyte contents were determined by flame atomic absorption spectroscopy.

\section{RESULTS AND DISCUSSION}

The enrichment factor (EF) was calculated from the following equation:

$$
\mathrm{EF}=\mathrm{k}_{2} / \mathrm{k}_{1}
$$

where, EF, $\mathrm{k}_{1}$ and $\mathrm{k}_{2}$ are standard for enrichment factor, the ratio of slope without preconcentration and the ratio of slope after preconcentration, respectively.

The extraction efficiency (E) of the cloud point extraction method, defined as the percentage of total analyte amount extracted into the surfactant-rich phase, can be expressed as the following equation:

$$
\mathrm{E}(\%)=\mathrm{C}_{\mathrm{s}} \mathrm{V}_{\mathrm{s}} / \mathrm{C}_{0} \mathrm{~V}_{0} \times 100
$$

where $\mathrm{E} \%, \mathrm{C}_{\mathrm{s}}, \mathrm{C}_{0}, \mathrm{~V}_{\mathrm{s}}, \mathrm{V}_{0}$ are the extraction efficiency, the metal concentrations in the surfactant-rich phase, the initial concentration in the aqueous phase, the volume of the surfactant-rich phase and the volume of the aqueous phase, respectively.

Characterization of the phase diagram of the DC-193water system: The phase diagram of the DC-193 obtained at different aqueous concentrations, ranging from $0.1-5 \%(\mathrm{v} / \mathrm{v})$.
The results are shown in Fig. 2. As can be seen, the shape of the curve coincides with that expected for a typical non-ionic surfactant. Below the curves, micellar solutions(1 L) exist, while two-phase regions coexist above the curves $(2 \mathrm{~L})$. And it can be seen from the Fig. 2 that the highest cloud point temperature value determined for DC-193 was $81{ }^{\circ} \mathrm{C}$ at the concentration of $0.5 \%(\mathrm{v} / \mathrm{v})$ and the lowest cloud point temperature was $72{ }^{\circ} \mathrm{C}$ at the concentration of $1.5 \%(\mathrm{v} / \mathrm{v})$.

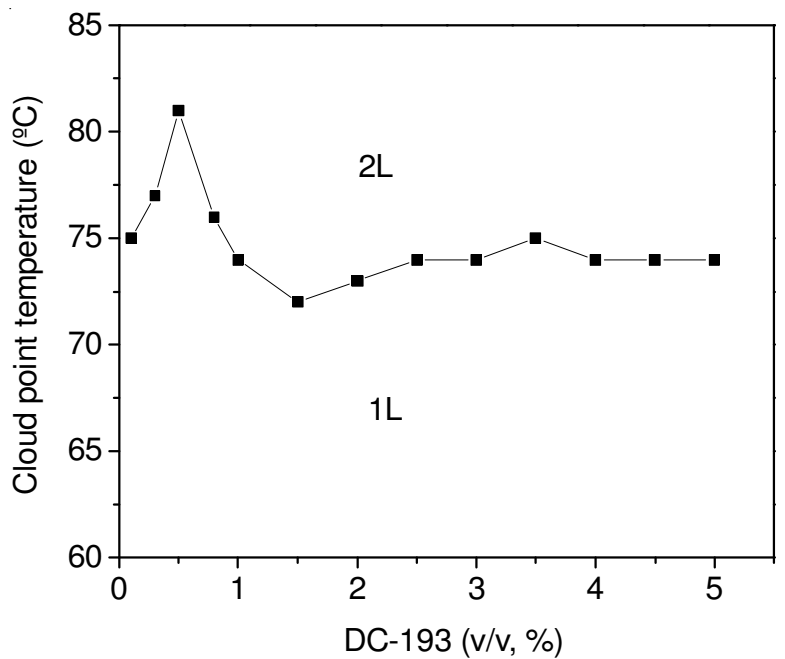

Fig. 2. Phase diagram of DC-193-water binary system. $1 \mathrm{~L}$, one phase; 2 L, two phases

Characterization of the phase diagram of the DC-193water-nonanoic acid system: The DC-193 as a non-ionic surfactant has a high cloud point, which is against the process of cloud point extraction. In this work, nonanoic acid was added to lower the cloud point of DC-193. And the results are shown in Fig. 3. As shown in Fig. 3, the nonanoic acid concentration of $8 \%(\mathrm{v} / \mathrm{v})$ was employed for the experiment.

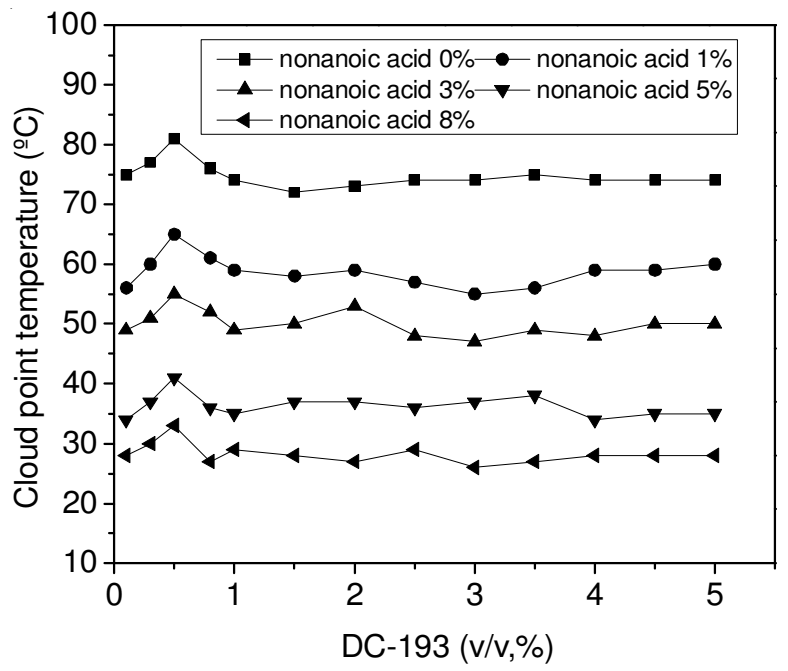

Fig. 3. Phase diagram of DC-193-water-nonanoic acid ternary system

Effect of pH: The pH was first critical parameter evaluated for its effect on the cloud point extraction and it plays a unique role in metal-chelate formation and subsequent extraction $^{22,23}$. Separation of metal ions by cloud point method involves the formation of a complex with sufficient hydro- 
phobicity to be extracted in to the small volume surfactant rich phase. For this purpose, the effect of sample $\mathrm{pH}$ (2-9) on the cloud point extraction of $\mathrm{Au}$ and $\mathrm{Ag}$ were investigated. The results are shown in Fig. 4. It can be seen from the Fig. 4 that the complex of Au and DDTC is stable in the $\mathrm{pH}$ range of 3-7 while that of Ag and DDTC is stable in the $\mathrm{pH}$ range of 5-7. In subsequent experiments, pH 5 was chosen as the optimum for further experiments.

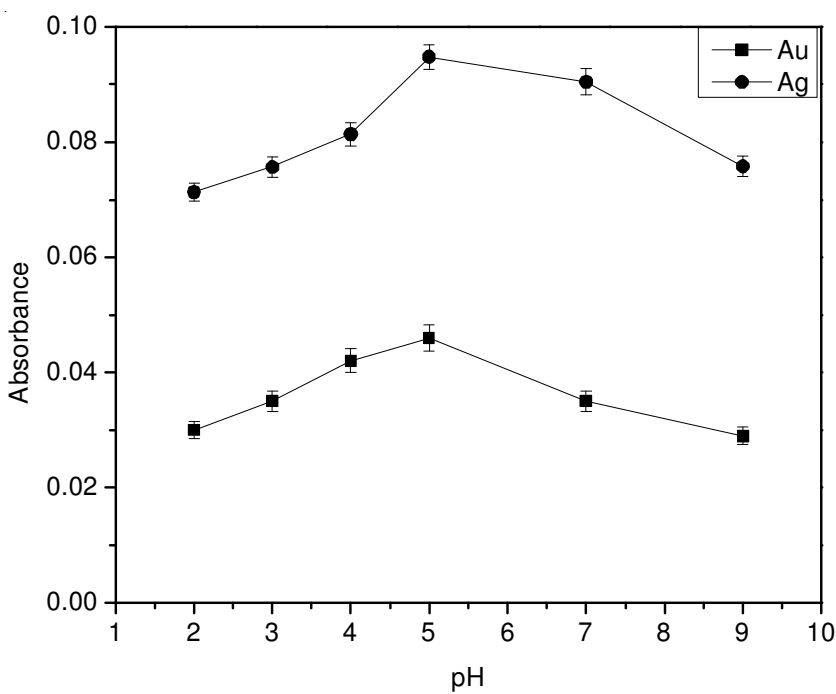

Fig. 4. Effect of $\mathrm{pH}$ on the absorbance of the complex: $0.5 \mu \mathrm{g} / \mathrm{mL}$ of $\mathrm{Au}$ and $\mathrm{Ag}, 7.0 \mu \mathrm{g} / \mathrm{mL}$ DDTC and $1.5 \%$ (v/v) DC-193

Effect of the diethyldithiocarbamate concentration: The effect of DDTC concentration in the range of $0.5 \mu \mathrm{g} / \mathrm{mL}$ to $9.0 \mu \mathrm{g} / \mathrm{mL}$ was investigated while the other experimental variables remained constant. The results are illustrated in Fig. 5. It could be seen that with the increase of DDTC concentration, the absorbance increases and a maximum is obtained after the DDTC concentration approaches to $5.0 \mu \mathrm{g} / \mathrm{mL}$ and remains constant up to $9.0 \mu \mathrm{g} / \mathrm{mL}$. Therefore, $7.0 \mu \mathrm{g} / \mathrm{mL}$ DDTC concentration was employed for further experiments.

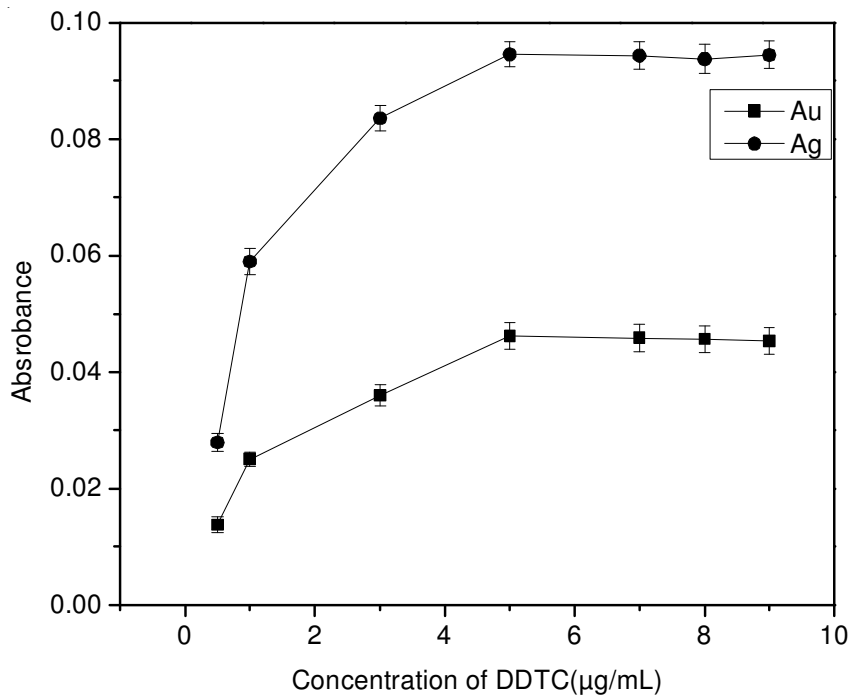

Fig. 5. Effect of DDTC concentration on the absorbance of complex: 0.5 $\mu \mathrm{g} / \mathrm{mL}$ of $\mathrm{Au}$ and $\mathrm{Ag}, \mathrm{pH} 5$ and $1.5 \%$ (v/v) DC-193
Effect of DC-193 concentration: The concentration of surfactant that is used in cloud point extraction is a critical factor. A successful cloud point extraction should maximize the extraction efficiency by minimizing the phase volume ratio. Therefore, the effect of variation of the concentration of DC-193 was examined. Fig. 6 shows the effect of DC-193 concentration on the absorbance in the range of $0.1-2 \%(\mathrm{v} / \mathrm{v})$. It could be seen that the absorbances of $\mathrm{Au}$ and $\mathrm{Ag}$ significantly increase when DC-193 concentration increases from 0.1 to $1.5 \%(\mathrm{v} / \mathrm{v})$. However, further increase in the concentration of DC-193 leads to gradual decrease in the absorbance of Au and Ag. A possible explanation might be that the increment in the volumes and the viscosity of the surfactant phase will result in poor sensitivity ${ }^{12,24}$. Accordingly, a DC-193 concentration of $1.5 \%(\mathrm{v} / \mathrm{v})$ was employed for the rest of experiment.

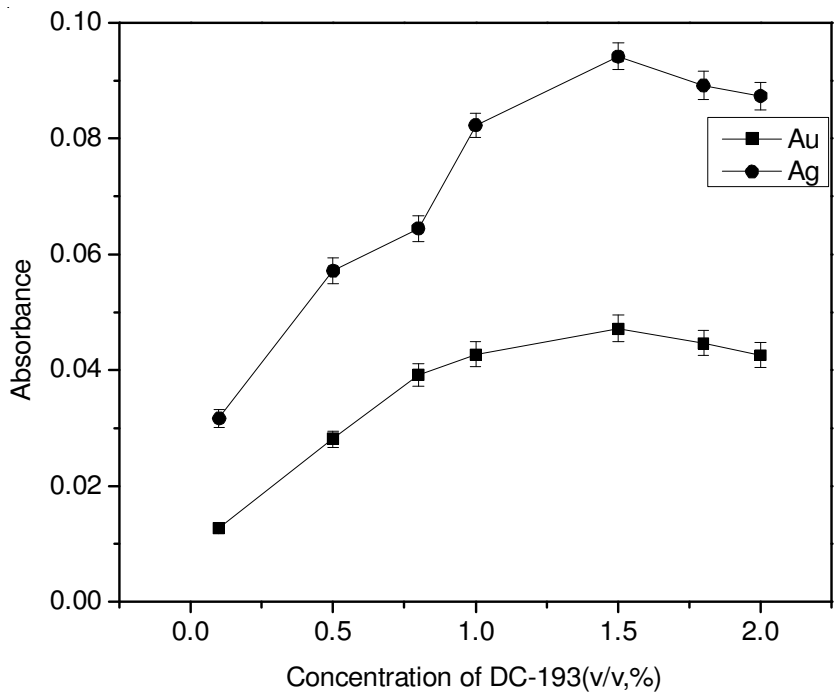

Fig. 6. Effect of DC-193 concentration on the absorbance of complex: 0.5 $\mu \mathrm{g} / \mathrm{mL}$ of $\mathrm{Au}$ and $\mathrm{Ag}, \mathrm{pH} 5$ and $7.0 \mu \mathrm{g} / \mathrm{mL}$ DDTC

Effects of different concentrations of different fatty acids on the cloud point for DC-193: In cloud point extraction, cloud point is an important influence factor which should be considered. Generally, the cloud point should be in the range of room temperature, while DC-193 as a non-ionic surfactant has a high cloud point. In this work, it is found that the cloud point for DC-193 would be dropped by adding fatty acids. Three kinds of fatty acids have been added in further experiment. The results are shown in Fig. 7. As can be seen, capric acid had the most obvious effect on dropping the cloud point. However, the speed of the phase separation was too slow. Accordingly, a nonanoic acid concentration of $8 \%(\mathrm{v} / \mathrm{v})$ is employed for the rest of this work.

Effects of equilibrium temperature and time: In cloud point extraction, it couldn't be better to employ the shortest incubation time and the lowest possible equilibration temperature as a compromise between completion of extraction and efficient separation of phases. An optimal equilibration temperature and incubation time are obbligato for complete reactions and to achieve easy phase separation and preconcentration as efficiently as possible $e^{25}$. For this reason, the effects of equilibration temperature and time have been studied with a range 
of $30-80^{\circ} \mathrm{C}$ and $10-120 \mathrm{~min}$, respectively. It was found that an equilibration temperature of $65^{\circ} \mathrm{C}$ and time of $50 \mathrm{~min}$ were adequate to achieve complete extraction.

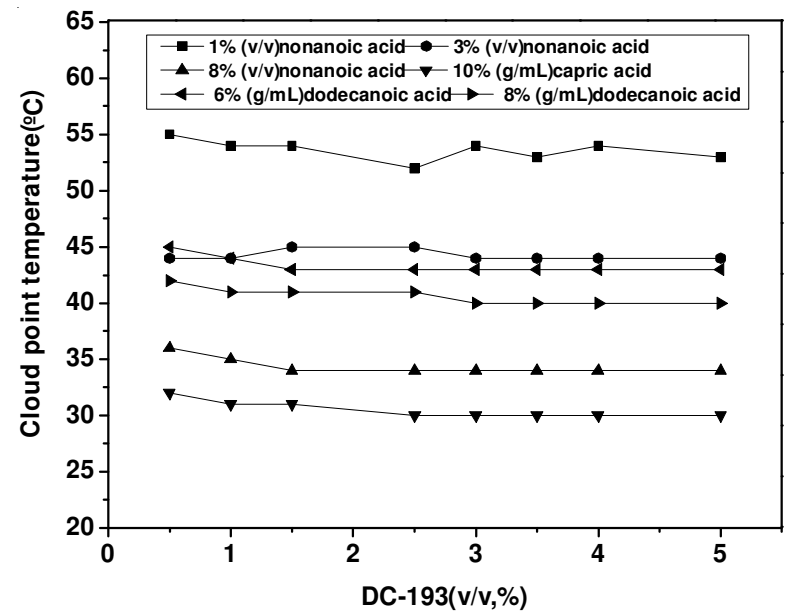

Fig. 7. Effect of different fatty acids on the cloud point for DC-193

Comparison of different surfactants: Triton X-114 is a classic non-ionic surfactant which is the most frequently used to perform cloud point extraction experiments. And it has also been used in determination of Au or Ag. In this work, DC-193 as a new non-ionic surfactant was used in determination of $\mathrm{Au}$ and $\mathrm{Ag}$ by cloud point extraction. And contrast experiment of the two kinds of surfactant was investigated. As shown in Fig. 8, it can be seen that compared with Triton X-114, DC193 as a non-ionic surfactant used in cloud point extraction had obtained the similar effect. In addition, DC-193 could obtain a smaller volume of surfactant-rich phase compared with Triton X-114 in the same concentration.

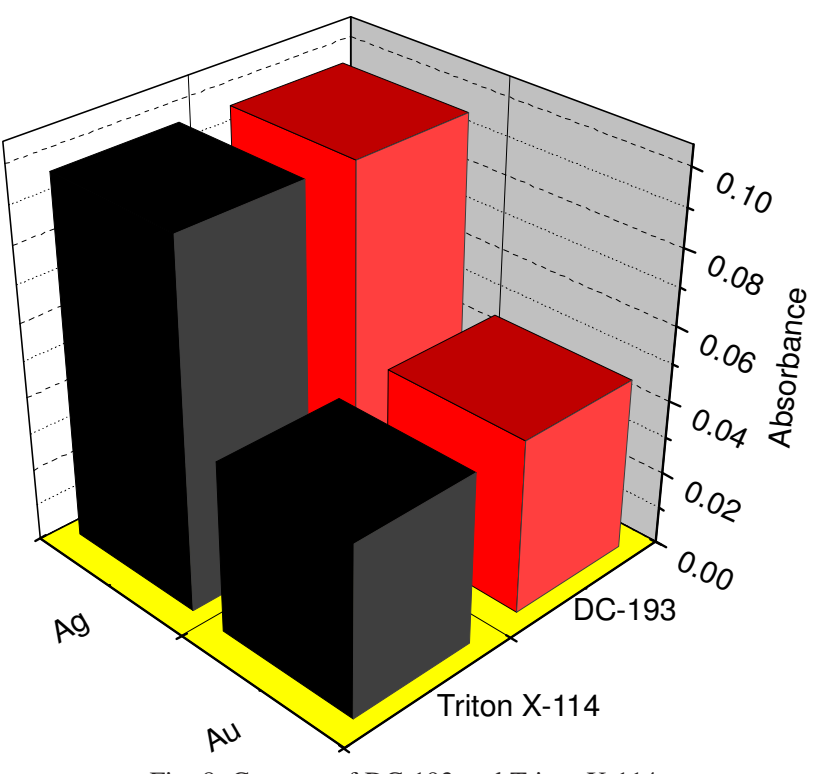

Fig. 8. Contrast of DC-193 and Triton X-114

Characteristics of the method: The analytical characteristics of the method were evaluated under the optimum experimental conditions. The enrichment factor $(\mathrm{EF})$, relative standard deviations and limits of detection are effective factors to evaluate a developed analytical method. With the optimized system, the calibration graph of $\mathrm{Au}$ and $\mathrm{Ag}$ were linear in the range of $10-500 \mu \mathrm{g} / \mathrm{L}$ and $10-800 \mu \mathrm{g} / \mathrm{L}$, respectively. The calibration equation is $\mathrm{A}=1.0 \times 10^{-4} \mathrm{C}+0.0057$ with a correlation coefficient of 0.9951 for $\mathrm{Au}$ and $\mathrm{A}=2.0 \times 10^{-4} \mathrm{C}+0.0132$ with a correlation coefficient of 0.9931 for $\mathrm{Ag}$, where $\mathrm{A}$ is the absorbance and $\mathrm{C}$ is the $\mathrm{Au}$ or $\mathrm{Ag}$ concentration in $\mu \mathrm{g} / \mathrm{L}$. The detection limits, defined as the concentration equivalent to three times the standard deviation $(\mathrm{n}=11)$ of the reagent blank, for $\mathrm{Au}$ and $\mathrm{Ag}$ were $3.4 \mu \mathrm{g} / \mathrm{L}$ and $2.7 \mu \mathrm{g} / \mathrm{L}$, respectively. The relative standard deviation for $\mathrm{Au}$ and $\mathrm{Ag}$ were $3.6 \%$ and 3.4 $\%(\mathrm{C}=0.5 \mu \mathrm{g} / \mathrm{mL}, \mathrm{n}=11)$. The enhancement factor, defined as the ratio of slope of preconcentrated samples to that obtained without preconcentration, were 25 and 20 for $\mathrm{Au}$ and $\mathrm{Ag}$, respectively.

Effects of foreign ions: In view of the high selectivity provided by flame atomic absorption spectroscopy, the interferences studied were those related to the preconcentration step $^{3,22}$. An ion was regarded as interfering when it caused a variation in the absorbance of the sample greater than $\pm 5 \%$ error $^{20}$. The interfering effects of some metal ions on the preconcentration and determination of $\mathrm{Au}$ and $\mathrm{Ag}$ were examined under the optimized conditions. To perform this study, the amounts of $\mathrm{Au}$ and $\mathrm{Ag}$ were set at $0.5 \mu \mathrm{g} / \mathrm{mL}$. The results are shown in Table-1. As it is seen, the ions normally present in mine samples have no considerable effect on the determination of $\mathrm{Au}$ and $\mathrm{Ag}$ under the experimental conditions employed.

\begin{tabular}{|c|c|c|c|c|c|}
\hline \multicolumn{6}{|c|}{$\begin{array}{c}\text { TABLE-1 } \\
\text { TOLERANCE LIMITS FOR THE DETERMINATION } \\
\text { OF } 0.5 \mu \mathrm{g} / \mathrm{mL} \mathrm{Au} \mathrm{AND} \mathrm{Ag}\end{array}$} \\
\hline \multirow[t]{2}{*}{ Ion } & \multirow[t]{2}{*}{$\begin{array}{l}\text { Added } \\
\text { as }\end{array}$} & \multicolumn{2}{|c|}{$\begin{array}{l}\text { Interfering ion to analyte } \\
\text { ratio }\end{array}$} & \multicolumn{2}{|c|}{$\begin{array}{c}\text { Recovery }(\%) \\
(\mathrm{n}=11)\end{array}$} \\
\hline & & $\mathrm{Au}$ & $\mathrm{Ag}$ & $\mathrm{Au}$ & $\mathrm{Ag}$ \\
\hline $\mathrm{K}^{+}$ & $\mathrm{KCl}$ & 1500 & 1000 & 96.5 & 98.4 \\
\hline $\mathrm{Na}^{+}$ & $\mathrm{NaCl}$ & 3000 & 2000 & 95.8 & 96.5 \\
\hline $\mathrm{Ca}^{2+}$ & $\mathrm{CaCl}_{2}$ & 1000 & 1000 & 98.6 & 98.5 \\
\hline $\mathrm{Mg}^{2+}$ & $\mathrm{MgCl}_{2}$ & 1000 & 1000 & 103.5 & 104.6 \\
\hline $\mathrm{Zn}^{2+}$ & $\mathrm{ZnCl}_{2}$ & 100 & 100 & 95.8 & 96.4 \\
\hline $\mathrm{Mn}^{2+}$ & $\mathrm{MnCl}_{2}$ & 100 & 100 & 100.6 & 101.4 \\
\hline $\mathrm{Fe}^{3+}$ & $\mathrm{FeCl}_{3}$ & 200 & 200 & 98.5 & 97.5 \\
\hline $\mathrm{Pb}^{2+}$ & $\mathrm{PbCl}_{2}$ & 100 & 100 & 97.3 & 96.7 \\
\hline $\mathrm{Cl}^{-}$ & $\mathrm{NaCl}$ & 3000 & 2000 & 102.4 & 103.6 \\
\hline $\mathrm{NO}^{3-}$ & $\mathrm{NaNO}_{3}$ & 2000 & 1500 & 103.2 & 104.2 \\
\hline $\mathrm{SO}_{4}{ }^{2-}$ & $\mathrm{Na}_{2} \mathrm{SO}_{4}$ & 500 & 1000 & 96.7 & 95.6 \\
\hline
\end{tabular}

Analysis of real samples: The proposed method was applied to the determination of gold and silver in water samples. Under the recommended experimental conditions, the developed method is employed to determine $\mathrm{Au}$ and $\mathrm{Ag}$ in water samples. And all the water samples are spiked with $\mathrm{Au}$ and $\mathrm{Ag}$ standard solutions at different concentration levels to assess the matrix effects. Non-spiked samples are also analyzed. The results are shown in Table-2. It shows that the developed method applied to the determination of $\mathrm{Au}$ and $\mathrm{Ag}$ in water samples.

\section{Conclusion}

A simple, sensitive and reliable cloud point extraction methodology has been established in the present work. DC193 as a silicone surfactant was used in the process of cloud 


\begin{tabular}{|c|c|c|c|c|}
\hline \multicolumn{5}{|c|}{$\begin{array}{c}\text { TABLE-2 } \\
\text { DETERMINATION OF Au AND Ag IN WATER SAMPLES }\end{array}$} \\
\hline $\begin{array}{l}\text { Water } \\
\text { sample }\end{array}$ & Element & $\begin{array}{l}\text { Added } \\
(\mu \mathrm{g} / \mathrm{L})\end{array}$ & $\begin{array}{l}\text { Found } \\
(\mu \mathrm{g} / \mathrm{L})\end{array}$ & $\begin{array}{l}\text { Recovery }(\%) \\
(\mathrm{n}=11)\end{array}$ \\
\hline \multirow[t]{6}{*}{1} & \multirow{3}{*}{$\mathrm{Au}$} & 0 & - & - \\
\hline & & 5 & 4.984 & 99.7 \\
\hline & & 10 & 10.260 & 102.6 \\
\hline & \multirow[t]{3}{*}{$\mathrm{Ag}$} & 0 & 5.310 & - \\
\hline & & 5 & 10.079 & 97.8 \\
\hline & & 10 & 15.286 & 99.8 \\
\hline \multirow[t]{6}{*}{2} & \multirow[t]{3}{*}{$\mathrm{Au}$} & 0 & 4.175 & - \\
\hline & & 5 & 9.182 & 100.1 \\
\hline & & 10 & 14.168 & 99.9 \\
\hline & \multirow[t]{3}{*}{$\mathrm{Ag}$} & 0 & 8.183 & - \\
\hline & & 5 & 13.174 & 99.9 \\
\hline & & 10 & 18.262 & 100.4 \\
\hline
\end{tabular}

point extraction with a good enrichment factor and low LOD. And the cloud point of DC-193 can be brought down by adding fatty acid. The proposed method was successfully applied for the determination of trace $\mathrm{Au}$ and $\mathrm{Ag}$ in water samples.

\section{ACKNOWLEDGEMENTS}

The work was supported by the Medical Neurobiology Key Laboratory of Kunming University of Science and Technology, Basic and Applied Research Project in Yunnan province (2008ZC082M), the Analysis and Testing Foundation of Kunming University of Science and Technology (No. 2010121) and Innovation Fund for Small and Medium Technology Based Firms (No. 11C26215305936).

\section{REFERENCES}

1. S.S. Tong, Q. Jia, N.Z. Song, W.H. Zhou, T.C. Duan and C.L. Bao, Microchim. Acta, 172, 95 (2011).
2. M.A.M. da Silva, V.L.A. Frescura and A.J. Curtius, Spectrochim. Acta $B, \mathbf{5 6}, 1941$ (2001)

3. L. Tavakoli, Y. Yamini, H. Ebrahimzadeh, A. Nezhadali, S. Shariati, F. Nourmohammadian, J. Hazard. Mater, 152, 737 (2008).

4. A.N. Tang, G.S. Ding and X.P. Yan, Talanta, 67, 942 (2005).

5. X.H. Zhu, X.S. Zhu and B.S. Wang, J. Anal. At. Spectrom., 21, 192 (2006).

6. J.L. Manzoori, H.A. Abdolmohammad-Zadeh and M. Amjadi, Microchim. Acta, 159, 71 (2007).

7. M. Ali and P.M. Javad, Asian J. Chem., 23, 1435 (2011)

8. G.Q. Xiang, S.P. Wen and X.Y. Wu, Asian J. Chem., 23, 1548 (2011).

9. L. Durukan, C.A. Sahin, N. Satiroglu and S. Bektas, Microchem. J., 99, 159 (2011)

10. M.A.M. da Silva, V.L.A. Frescura, F.J.N. Aguilera and A.J. Curtius, J. Anal. At. Spectrom., 13, 1369 (1998).

11. M.A.M. da Silva, V.L.A. Frescura and A.J. Curtius, Spectrochim. Acta $B, \mathbf{5 5}, 803$ (2000).

12. M. Ghaedi, A. Shokrollahi, K. Niknam, E. Niknam, A. Najibi and M. Soylak, J. Hazard. Mater., 168, 1022 (2009).

13. L. Yang, F.Q. Zhou, R.H. Huang, Z.H. Liu and Y.Y. Luo, J. Anal. Sci., 24, 185 (2008)

14. W.S. El-Naggar, T.A. Lasheen, E.A. Nouh and A.K. Ghonaim, Cent. Eur. J. Chem., 8, 34 (2010)

15. A.S.H. Dehghan, M. Hosseini and M. Salavati-Niasari, Asian J. Chem., 20, 4291 (2008).

16. S.Q. Chen and X.S. Zhu, Miner. Eng., 23, 1152 (2010).

17. P.M. Javad and M. Ali, Asian J. Chem., 23, 1424 (2011).

18. M. Ali and T. Nilofar, Asian J. Chem., 22, 5025 (2010).

19. A.B. Tabrizi, Bull. Korean Chem. Soc., 27, 1780 (2006)

20. F. Shemirani, S.D. Abkenar and A. Khatouni, Bull. Korean Chem. Soc., 25, 1133 (2004).

21. B.J. Yao, L. Yang, Q. Hu and S. Akita, Chin. J. Chem. Eng., 15, 468 (2007).

22. H.L. Ulusoy, R. Gurkan, U. Aksoy and M. Akcay, Microchem. J., 99, 76 (2011).

23. C.G. Yuan, K. Lin and A.L. Chang, Microchim. Acta, 171, 313 (2010).

24. D.L.G. Borges, M.A.M.S. da Veiga, V.L.A. Frescura, B. Welz and A.J. Curtius, J. Anal. At. Spectrom., 18, 501 (2003).

25. F. Shemirani, R.R. Kozani, Y. Assadi, Microchim. Acta, 157, 81 (2007). 